mixed with $3-4 / \mathrm{s}$ waves $(>200 \mathrm{mcV})$ posteriorly, mainly with eye-closure. Discharges mixed with slow components on eye-closure was the most frequent finding in patients aged 11 months to $>12$ years. (Boyd SG et al. Eur J Pediatr 1988;147:508-513). Six children had no history of seizures and the EEG features helped identify patients at an early age.

The EEG findings in the present report are comparable to those of Boyd, and a notched delta pattern, also characteristic of Angelman syndrome, is found in patients presenting $<4$ years of age. Researchers at the Epilepsy Center, Children's Memorial Hospital, Chicago, evaluated the notched delta pattern in diagnosis of patients with a suggestive phenotype of Angelman syndrome. A retrospective review of video-EEG recordings with notched delta pattern found 38\% specificity for Angelman syndrome. (Korff CM, Kelley KR, Nordli DR. J Clin Neurophysiol 2005;22(4):238-243).

\title{
INFECTIOUS DISEASES
}

\section{EPILEPTOGENESIS IN CALCIFIED NEUROCYSTICERCOSIS}

Researchers at Sanjay Gandhi Post Graduate Institute of Medical Sciences, Lucknow, India, and University of Texas Medical School at Houston performed dynamic contrast-enhanced (DCE) MRI and determined serum matrix metalloproteinase-9 (MMP9) levels and MMP-9 gene polymorphisms in 30 subjects with a single calcified lesion of neurocysticercosis without any perilesional abnormality. These measures showed significant differences between 2 groups, each containing 15 patients, one with and one without seizures. In symptomatic subjects, serum MMP-9 levels and MMP-9 gene polymorphisms, the determinants of blood brain barrier permeability, were significantly higher compared with asymptomatic subjects with calcified cysticercus lesions and controls. There may be different degrees of perilesional inflammation with similar MRI calcified neurocysticercosis lesions in patients with or without seizures. The subject's threshold of inflammation probably determines the occurrence of seizures. (Gupta RK, Awasthi R, Rathore RKS, et al. Understanding epileptogenesis in calcified neurocysticercosis with perfusion MRI. Neurology Feb 28, 2012;78:618-625). (Response and reprints. Prof Gupta: E-mail: rgupta@sgpgi.ac.in).

COMMENT. Albendazole and praziquantel, the two antiparasitic drugs used in treatment of neurocysticercosis, hasten radiologic resolution of cysts but may exacerbate the seizures resulting from the host inflammatory response. In patients with single inflamed brain parenchymal cysts, treatment is often withheld and is controversial. Approximately $10-20 \%$ of single cysticercal granuloma heal by calcification, and these patients are at higher risk of developing epilepsy (Rathore C et al. Editorial. Neurology 2012;78:612-613). Treatment is usually recommended for patients with nonenhancing or multiple cysticerci, and coadministration of corticosteroids for the first 2 or 3 days of therapy may decrease adverse effects. Arachnoiditis, vasculitis, or diffuse cerebral edema (cysticercal encephalitis) is treated with corticosteroids and albendazole or praziquantel. Anticonvulsant treatment is recommended until seizures are controlled for 1 to 2 years and there is radiological evidence of resolution. Calcified cysts usually require indefinite anticonvulsant therapy. Neurosurgery is indicated in patients with single intraventricular 
cysts and hydrocephalus. An ocular cyst should be ruled out before treatment with albendazole that may exacerbate inflammation. (American Academy of Pediatrics Red Book, $27^{\text {th }}$ ed, Elk Grove Village, IL, AAP, 2006, pp 646-7).

\section{LYME NEUROBORRELIOSIS AND ALICE IN WONDERLAND SYNDROME}

Pediatric neurologists at the Floating Hospital, Tufts University, Boston, MA report a 7-year-old boy with Alice in Wonderland syndrome associated with Lyme disease. He initially awakened with a nightmare, scared and screaming, saying that "his mind was running fast" and he heard "baseball fans cheering." He vomited the following day but had no headache. Three nights later he awoke, went down stairs, and was pale and scared. He had repetitive swallowing and lip-smacking and said "my head is running fast." Next evening while reading, the book appeared to be a distance away, and he said the letters were becoming smaller.

During 36 hours of video EEG recording he had 3 events of distorted perception, a feeling of becoming smaller and the book print farther away, none associated with evidence of seizure. A Lyme disease test at the $6^{\text {th }}$ day, performed at the insistence of the mother, was positive. CSF revealed lymphocytes $22 / \mathrm{mm} 3$, protein $23 / \mathrm{mg} / \mathrm{dl}$, and glucose $63 \mathrm{mg} / \mathrm{dl}$. Lyme disease Western blot immunoglobulin $\mathrm{M}$ on $10^{\text {th }}$ day tested positive in serum and CSF. Lyme PCR on CSF was negative and MRI was normal. He was treated with IV ceftriaxone for 21 days, and symptoms resolved after 3 days. He had no rash and no recurrence at 12-month follow-up. No personal or family history of migraine or epilepsy was elicited. Alice in Wonderland syndrome, or metamorphopsia, should be added to the clinical spectrum of Lyme neuroborreliosis, and a high index of suspicion is required in diagnosis. (Binalsheikh IM, Griesemer D, Wang S, Alvarez-Altalef R. Lyme neuroborreliosis presenting as Alice in Wonderland syndrome. Pediatr Neurol March 2012;46;185-186). (Response: Dr Binalsheikh. E-mail: alsheikh55@yahoo.com).

COMMENT. "Curiouser and curiouser!" said Alice, when she grew and expanded like a telescope after eating the cake. Distortions of form, size, movement, color, or sense of time are characteristic of metamorphopsia that may occur as a sensory aura during migraine or frontal lobe epilepsy. A PubMed literature search lists reports of several infectious agents associated with Alice in Wonderland syndrome, including Epstein-Barr virus, varicella, coxsackievirus B1, H1N1 influenza virus, and infectious mononucleosis. Lyme disease in the Tufts' case presents with visual and other illusions without systemic manifestations of neuroborreliosis. Alice in Wonderland syndrome is a benign disorder of childhood caused most frequently by migraine or Epstein-Barr virus infection. (Losada-Del Pozo R et al. Rev Neurol 2011;53(11):641-648).

\section{CEREBRAL MALFORMATIONS}

\section{HEMORRHAGE RISK OF CAVERNOUS MALFORMATION}

Researchers at the Mayo Clinic, Rochester, MN reviewed the records and radiograph data of 292 patients $(47.3 \%$ male) seen between 1989 and 1999 with a 